\title{
ORIGINAL
}

PROF-925

\section{TRIGEMINAL NEURALGIA}

\author{
DR. SHAHZAD SHAMS \\ FRCS, FCPS (Neurosurgery) \\ Fellowship in Neurosurgery (USA) \\ Associate Professor \\ Department of Neurosurgery \\ Services Hospital/SIMS, Lahore
}

\author{
DR. FARHAN SHAHZAD BUTT, MBBS \\ Medical Officer \\ Department of Neurosurgery \\ Services Hospital/SIMS, Lahore \\ Copyrights: 16 June, 2005.
}

\begin{abstract}
Objectives: trigeminal Neuralgia is a severe lancinating pain and is associated with conflict between a vessel and $5^{\text {th }}$ cranial nerve. Micro vascular Decompression (MVD) of the nerve relieves this pain. Material \& Methods: We reviewed 60 patients who underwent MVD for medically intractable trigeminal neuralgia. The outcome of procedure was assessed retrospectively. Results: Preoperative symptoms ranged from 3 months to 10 years. Right side of face was affected in 32 and left in 28 patients. Mandibular division (21.6\%) was the most commonly involved branch for referred pain. Superior cerebellar artery was the commonest offending vessel in $86.6 \%$ of cases. Trigeminal root entry zone location (70\%) was the commonest site of conflict. Postoperative pain relief showed excellent results in $86.6 \%$, good in $10.0 \%$ and poor in $3.4 \%$. Recurrence rate was $1.5 \%$ per year. Conclusion: MVD is safe, effective and treatment of choice for trigeminal neuralgia.
\end{abstract}

Key Words: Trigeminal Neuralgia, Offending Vessel, Microvascular Decompression.

\section{INTRODUCTION}

Microvascular Decompression was first introduced by Dandy in 1934 and later popularized by Peter Jannetta ${ }^{1,2}$.

Trigeminal Neuralgia is a severe lancinating shock like pain within the distribution of $5^{\text {th }}$ cranial nerve. Usually these patients present after multiple visits to dental surgeons and local General Practitioner and Physicians.

The cause of this pain has been associated with conflict between a vessel and the $5^{\text {th }}$ cranial nerve from its origin from brainstem to its exit at Meckle's cave . $^{3}$

In order to perform Microvascular Decompression, microscope, micro-surgical instruments and application of microsurgical techniques are mandatory ${ }^{4}$.

\section{MATERIAL AND METHOD}

We reviewed 60 cases of trigeminal neuralgia in whom Microvascular Decompression was done between 2000 2004. There were 34 females and 26 males, age ranged between 20 to 70 years. CT or MRI was performed in all 
cases.

Carbamazepine, phenytion and Baclofen were used as a single drug or in combination in all patients prior to surgery. Surgery was only performed when pain become intractable despite medical treatment.

Under general anesthesia lateral position was made and post auricular $6 \mathrm{~cm}$ incision was made in all cases. Retro-mastoid $5 \mathrm{~cm}$ craniotomy was done after opening dura crescentically, cerebellar hemisphere was retracted. Angle between transverse and sigmoid sinus was exposed. The arachnoid layer was divided, conflict between the vessel and 5th nerve was identified. Compressive vessel was dug out from indentation site by micro vascular techniques. The Teflon prosthesis was placed between vessel and nerve to relocate the vessel.

\section{RESULTS}

Preoperative symptoms ranged between 3 months to 10 years. Right side face was affected in 32 and left side in 28 cases.

Trigeminal root entry zone is the portion of the $5^{\text {th }}$ nerve which belongs to the central nervous system and is the site which is involved most commonly which means this area has to be explored in all cases even though conflict is seen in the mid or exit of the nerve. When distortion of nerve was observed results were excellent.

\begin{tabular}{|c|c|c|}
\hline \multicolumn{3}{|c|}{ Table I. Branch Distribution of Referred pain } \\
\hline Branch & \%age & No. of pts \\
\hline V1 & $01.6 \%$ & 1 \\
\hline V2 & $18.3 \%$ & 11 \\
\hline V3 & $21.6 \%$ & 13 \\
\hline V1+V2 & $20.0 \%$ & 12 \\
\hline V2+V3 & $25.0 \%$ & 15 \\
\hline V, V2+V3 & $13.3 \%$ & 15 \\
\hline \multicolumn{2}{|c|}{ V1=0pthalmic, V2=Maxillary, V3=Mandibular } \\
\hline
\end{tabular}

Branch distribution of referred pain is listed in table I. Offending vessels involved are shown in table II. Location of neurovascular conflict is summarized in table III while degree of conflict is shown in table IV. Relationship of vessel with nerve and complications are summarized in table V\& VI respectively.

Factors for good outcome were short duration, typical presentation, single artery compression and complete decompression.

\begin{tabular}{|c|c|c|}
\hline \multicolumn{3}{|c|}{ Table II. Offending Vessels Involved } \\
\hline Offending Vessels & $\%$ age & No. of pts \\
\hline Superior cerebellar artery & $86.6 \%$ & 52 \\
\hline Antero-Inferior cerebellar artery & $25.0 \%$ & 15 \\
\hline Transverse pontine vein & $26.6 \%$ & 16 \\
\hline
\end{tabular}

\begin{tabular}{|c|c|c|}
\hline \multicolumn{3}{|c|}{ Table III. Location of Neurovascular Conflict } \\
\hline Location of Conflict & $\%$ age & No. of pts \\
\hline Trigeminal root entry zone & $70.0 \%$ & 42 \\
\hline Mid third of nerve & $23.3 \%$ & 14 \\
\hline Exit at Meckle's Cave & $06.6 \%$ & 4 \\
\hline
\end{tabular}

\begin{tabular}{|c|c|c|}
\hline \multicolumn{2}{|c|}{ Table IV. Degree of Conflict } \\
\hline Degree of conflict & $\%$ age & No. of patients \\
\hline Simple contact & $10.0 \%$ & 6 \\
\hline Distortion of nerve & $48.3 \%$ & 29 \\
\hline marked indentation & $41.6 \%$ & 25 \\
\hline
\end{tabular}

Factors for worse outcome were venous compression, longer duration, a typical presentation and partial decompression. Recurrence meant transition from excellent outcome to good or poor outcome. Five patients developed recurrence within two year. These were in the initial learning period in the first year of study. The annual risk of recurrence is about $1.5 \%$ per year. Recurrence was treated with resumption of 
medication, second MVD operation and/or ablative procedure.

Excellent results means complete relief of pain. Good results meant $75 \%$ reduction in pain. Poor results meant more than $25 \%$ of preoperative level of pain leading to resumption of medication, second surgery or ablative procedure (Table VII).

\begin{tabular}{|c|c|c|}
\hline \multicolumn{3}{|c|}{ Table V. Relationship of vessels with Nerve } \\
\hline Position of Vessel & $\%$ age & No. of patients \\
\hline Supero-medial & $60.0 \%$ & 36 \\
\hline Supero-lateral & $31.6 \%$ & 19 \\
\hline Inferior & $08.4 \%$ & 5 \\
\hline
\end{tabular}

\begin{tabular}{|c|c|c|}
\hline \multicolumn{3}{|c|}{ Table VI. Complications } \\
\hline Complications & $\%$ age & No. of patients \\
\hline Mild hearing loss & $3.3 \%$ & 2 \\
\hline Transient diplopia & $1.6 \%$ & 1 \\
\hline Transient facial weakness & $3.3 \%$ & 2 \\
\hline CSF leak & $3.3 \%$ & 2 \\
\hline Chemical meningitis & $6.6 \%$ & 4 \\
\hline
\end{tabular}

\begin{tabular}{|c|c|c|}
\hline \multicolumn{3}{|c|}{ Table VII. Post Operative Pain Relief } \\
\hline Post op pain relief & \%age & No. of patients \\
\hline Complete (Excellent) & $86.6 \%$ & 52 \\
\hline Partial (Good) & $10.0 \%$ & 6 \\
\hline Absent (Poor) & $03.4 \%$ & 2 \\
\hline
\end{tabular}

Complete decompression and relocation and placement of prosthesis are mandatory to have excellent result.

\section{DISCUSSION}

Trigeminal neuralgia is a troublesome disease. The relief provided by drugs decreases over time ${ }^{5}$. About half of all patients require an operation for pain relief ${ }^{6}$.
Female sex and a longer preoperative history of tic have been reported as risk factors for recurrence after microvascular decompression ${ }^{7}$.

Ataxia, disequilibrium and gait disturbances sometimes found in early postoperative period at hospital discharge are usually fully recovered within 2 weeks ${ }^{8}$.

Low rates of severe postoperative facial numbness $1 \%$ and dysaesthesia in our study is an advantage when compared to radio frequency thermal rhizotomy ${ }^{9}$ and glycerol rhizotomy ${ }^{10}$.

Operative findings are also corrected with outcome, more severe vascular compression of trigeminal root had more successful relief of symptoms after MVD ${ }^{11}$.

Recurrence rate in our study was $1.5 \%$ per year is comparable to international studies ${ }^{12}$. The mandatory exploration of root entry zone has led to decreased recurrence rate ${ }^{13}$.

In the follow-up, our results are in the range of reported series $^{14,}$.

\section{CONCLUSION}

MVD is safe, effective and treatment of choice for intractable pain which is recommended for all ages with minimal complications.

\section{REFERENCES}

1. Pollack IF, Jannetta PJ, Bissonette DG. Bilateral Trigeminal neuralgia: a 14 year experience with microvascular decompression. J Neurosurg 68: 559$565,1998$.

2. Sweet WH, Wepsic JG. Controlled Thermocoagulation of Trigeminal ganglion and routlets for different destruction of pain fibers. I, Trigeminal neuralgia. J Neurosurg 40: 143-156, 1974.

3. Barker FG $2^{\text {nd }}$, Jannetta PJ, Bissonette DG, Larkins MV Jho HD. The long term outcome of microvascular for trigeminal neuralgia. N Engl J Med. 25: 1125-6, 1996.

4. Kolluri S, Heros RC, Microvascular decompression for 
trigeminal neuralgia: a five year follow up study. Surg Neuro. 22: 235-240, 1984.

5. Taylor JC, Brauer S, Espir ML. Long term treatment of trigeminal neuralgia with carbamazepine. Postgrad Med J 57: 16-18, 1981.

6. Kalknis SN, Eskandar En, Carter BS, Barker FG $2^{\text {nd }}$. Microvascular decompression surgery in the United States, 1996-2000: mortality rates, morbidity rates, and the effects of the hospital and surgeon volumes. Neurosurgery, 52(6): 1251-61, 2003.

7. Kureshi SA, Wilkins RH. Posterior fossa re-exploration for persistent or recurrent trigeminal neuralgia or hemifacial spasm: surgical findings and therapeutic implications. Neurosurgery . 43(5): 1111-7, 1998.

8. Li St, Pan Q, Liu N, Shen F, Liu Z, Guan Y, Trigeminal neuralgia: what are the important factors for good operative outcomes with microvascular decompression. Surg Neurol 62(5): 500-4, 2004.

9. Bederson JB, Wilson CB. Evaluation of microvascular decompression and partial sensory rhizotomy in $\mathbf{2 5 2}$ cases of trigeminal neuralgia. J Neurosurg 71: 359-367, 1989.
10. Hakanson S. Trigeminal neuralgia treated by the injection of glycerol into the trigeminal cistern. Neurosurgery 9: 638-464, 1981.

11. Sindou M, Howeidy $T$, Acevedo G. Anatomical observations during microvascular decompression for idiopathic trigeminal neuralgia with correlations between topography of pain and site of the neurovascular conflict. Prospective study in a series of 579 patients. Acta Neuochir (Wien). 144(1): 1012, 2002.

12. Sun $T$, Saito $S$, Nakai $O$, Ando $T$. Long term results of microvascular decompression for trigeminal neuralgia with reference to probability of recurrence. Acta Neurochir (Wein) 126: 144-148, 1994.

13. De Ridder D, Moller A, Verlooy J, Cornelissen M, De Ridder I. Is the root entry/exist zone important in microvascular compression syndromes? Neurosurgery. 51(2): 427-33, 2002.

14. Mendoza N, Illingworth RD, Trigeminal neuralgia treated by microvascular decompression: along term up follow up study. Br j Neurosurg 9: 13-19, 1995.

\section{"INNOVATE"; That's the future.}

Shuja Tahir 